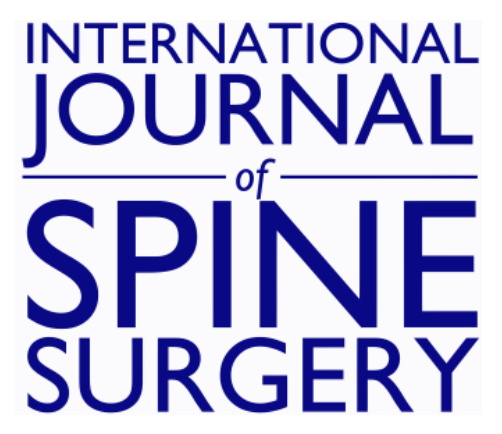

\title{
Spinal Cord Drift Following Laminoplasty Versus Laminectomy and Fusion for Cervical Spondylotic Myelopathy
}

Adedayo O. Ashana, Remi M. Ajiboye, William L. Sheppard, Chad R. Ishmael, Jeremiah Y. Cohen, Joel S. Beckett and Langston T. Holly

Int J Spine Surg 2021, 15 (2) 205-212

doi: https://doi.org/10.14444/8028

http://ijssurgery.com/content/15/2/205

This information is current as of April 25, 2023.

Email Alerts Receive free email-alerts when new articles cite this article. Sign up at:

http://ijssurgery.com/alerts

The International Journal of Spine Surgery

2397 Waterbury Circle, Suite 1,

Aurora, IL 60504, Phone: +1-630-375-1432 


\title{
Spinal Cord Drift Following Laminoplasty Versus Laminectomy and Fusion for Cervical Spondylotic Myelopathy
}

\author{
ADEDAYO O. ASHANA, MD,${ }^{1}$ REMI M. AJIBOYE, MD,${ }^{1}$ WILLIAM L. SHEPPARD, MD,${ }^{1}$ CHAD R. \\ ISHMAEL, MD ${ }^{1}{ }^{\mathrm{JEREMIAH}}$ Y. COHEN, MD ${ }^{1}$ JOEL S. BECKETT, MD ${ }^{2}$ LANGSTON T. HOLLY, MD ${ }^{1,2}$ \\ ${ }^{1}$ Department of Orthopaedic Surgery, University of California, Los Angeles, California, ${ }^{2}$ Department of Neurosurgery, University of California, Los Angeles, \\ California
}

\begin{abstract}
Background: Cervical laminoplasty and laminectomy and fusion (LF) are posterior-based surgical techniques for the surgical treatment of cervical spondylotic myelopathy (CSM). Interestingly, the comparative amount of spinal cord drift obtained from these procedures has not been extensively described. The purpose of this study is to compare spinal cord drift between cervical laminoplasty and LF in patients with CSM.

Methods: The laminoplasty group consisted of 22 patients, and the LF group consisted of 44 patients. Preoperative and postoperative alignment was measured using the Cobb angle (C2-C7). Spinal cord position was measured on axial T2-magnetic resonance imaging of the cervical spine preoperatively and postoperatively. Spinal cord drift was quantified by subtracting preoperative values from postoperative values. Functional improvement was assessed using the modified Japanese Orthopaedic Association (mJOA) score.

Results: Mean spinal cord drift was higher following LF compared to laminoplasty $(2.70 \mathrm{vs} 1.71 \mathrm{~mm}, P<.01)$. Using logistic regression analysis, there was no correlation between sagittal alignment and spinal cord drift. Both groups showed an improvement in mJOA scores postoperatively compared to their preoperative values (laminoplasty, $+2.0, P=$ $.012 ; \mathrm{LF},+2.4, P<.01)$. However, there was no difference in mJOA score improvement postoperatively between both groups $(P=.482)$.

Conclusions: This study demonstrates that patients who had LF for CSM achieved more spinal cord drift postoperatively compared to those who had laminoplasty. However, the increased drift did not translate into superior functional outcome as measured by the mJOA score.

Level of Evidence: 3.

Clinical Relevance: Spinal cord drift following LF may differ from laminoplasty in patients undergoing surgery for CSM. This finding should be considered when assessing CSM patients for surgical intervention.
\end{abstract}

Cervical Spine

Keywords: laminoplasty, laminectomy, fusion, cervical, myelopathy, drift, spinal cord

\section{INTRODUCTION}

Cervical spondylotic myelopathy (CSM) is commonly a debilitating disorder, often resulting in significant neurological deterioration over time. CSM remains the leading cause of spinal cord dysfunction worldwide. ${ }^{1}$ Historically, surgical treatment has been the mainstay for progressive CSM. However, the optimal surgical technique for treating CSM remains controversial. Determining the most appropriate surgical approach is often dictated by patient age, source and location of compressive pathology, number of levels involved, spinal alignment, presence of instability, and patient and surgeon preference. Both laminoplasty and lami- nectomy and fusion (LF) are posterior-based surgical techniques most commonly used in the treatment of CSM. ${ }^{2,3}$ Posterior approaches are particularly attractive in the setting of multilevel disease because of a lower risk of approach-related complications. ${ }^{4}$

The primary decompressive effect from these procedures is presumed to occur from dorsal drift of the spinal cord in an expanded canal following surgery. ${ }^{5}$ Therefore, the presence of lordotic cervical alignment is frequently desired to potentiate dorsal drift of the cord. While the literature has consistently shown this to be true following laminoplasty, 
Table 1. Baseline patient demographics and characteristics.

\begin{tabular}{|c|c|c|c|}
\hline & Laminoplasty & Laminectomy & $P$ Value \\
\hline Patients & 22 & 44 & \\
\hline Gender & 29 males $(65.9 \%)$ & 12 males $(77.2 \%)$ & .36 \\
\hline Age, mean $\pm \mathrm{SD}, \mathrm{y}$ & $54.5 \pm 9.6$ & $65.1 \pm 10.1$ & $<.01$ \\
\hline Time between preoperative and postoperative MRI, mean $\pm \mathrm{SD}$, mo & $16.2 \pm 19.07$ & $15.62 \pm 21.29$ & .91 \\
\hline Time between surgery and postoperative MRI, mean $\pm \mathrm{SD}$, mo & $10.08 \pm 12.87$ & $10.67 \pm 13.4$ & .86 \\
\hline Baseline mJOA, mean \pm SD & $13.6 \pm 1.6$ & $13.3 \pm 2.6$ & .59 \\
\hline Levels affected, mean $\pm \mathrm{SD}$ & $2.9 \pm 1.0$ & $3.5 \pm 0.8$ & .03 \\
\hline Cord signal, mean $\pm \mathrm{SD}$ & $0.7 \pm 0.5$ & $0.7 \pm 0.5$ & .66 \\
\hline
\end{tabular}

Abbreviations: mJOA, modified Japanese Orthopaedic Association; MRI, magnetic resonance imaging; SD, standard deviation.

drift has been obtained following LF even in the presence of preoperative kyphosis. ${ }^{5-14}$

This suggests possible mechanistic differences between laminoplasty and LF. Interestingly, the comparative amount of dorsal spinal cord drift obtained from these procedures has not been extensively described. Furthermore, there are comparatively limited data on the relationship of preoperative alignment to drift following LF. The goal of this study is to (1) compare spinal cord drift between cervical laminoplasty and LF and (2) determine if preoperative cervical alignment affected drift in patients who underwent LF. As a secondary measure, the amount of drift obtained will be correlated to functional outcome using the modified Japanese Orthopedic Association (mJOA) score.

\section{MATERIALS AND METHODS}

\section{Study Population}

The study was reviewed and approved by the institutional review board at our institution. The medical records, preoperative and postoperative radiographs, and magnetic resonance imaging (MRI) of the cervical spine were reviewed on all patients undergoing laminoplasty or laminectomy with posterior instrumented fusion by the senior author (L.T.H.) at more than 1 consecutive level for CSM over an 8-year period. Significant kyphosis and instability were contraindications to laminoplasty, while fixed severe kyphosis was a contraindication for LF. Postoperative MRI was routinely obtained in these patients as part of another NIH funded clinical study.

Exclusion criteria for this study included patients with a history of previous cervical spine surgery; concomitant anterior cervical spine surgery; a diagnosis of infection, tumor, central cord syndrome, or other acute traumatic event; the simultaneous presence of other diagnosed neurological disorder (such as normal pressure hydrocephalus,
Parkinson's disease, polio, or multiple sclerosis); or postoperative MRIs less than 3 months from surgery and patients whose MRIs were significantly degraded secondary to metallic artifact or patient movement. Based on the above inclusion and exclusion criteria, 66 patients were enrolled in the study and divided into 2 groups. The laminoplasty group (A) consisted of 22 patients (17 men and 5 women). The LF group (B) consisted of 44 patients (29 men and 15 women; Table 1).

\section{Surgical Management}

All patients in group A underwent laminoplasty using the modified open-door laminoplasty technique with titanium miniplates with or without allograft bone, as previously described. ${ }^{15}$ A $10-\mathrm{mm}$ plate/and or bone graft was used uniformly. All patients in group B underwent a posterior instrumented fusion in addition to decompressive laminectomy. The fusion procedures were performed using bilateral lateral mass screws and rods with local autograft bone.

\section{Radiographic Analysis}

Radiographic analysis of preoperative and postoperative MRIs were performed using a single picture archiving and communication system viewer and imaging software (Centricity, GE Medical Systems, Milwaukee, Wisconsin). The presence of preoperative spinal cord T2-MRI signal hyperintensity was assessed. Anatomical measurements were performed using digital calipers at uniform magnification $(200 \%)$. Preoperative and postoperative cervical alignment was measured by the Cobb angle (C2-C7). Lordotic spine was defined as Cobb angle $>10^{\circ}$, straight as $0-10^{\circ}$, and kyphotic as $<0^{\circ}$.

The spinal cord position was measured on axial T2-MRI of the cervical spine preoperatively and postoperatively. The midpoint of the spinal cord was determined by adding the anterior spinal cord 


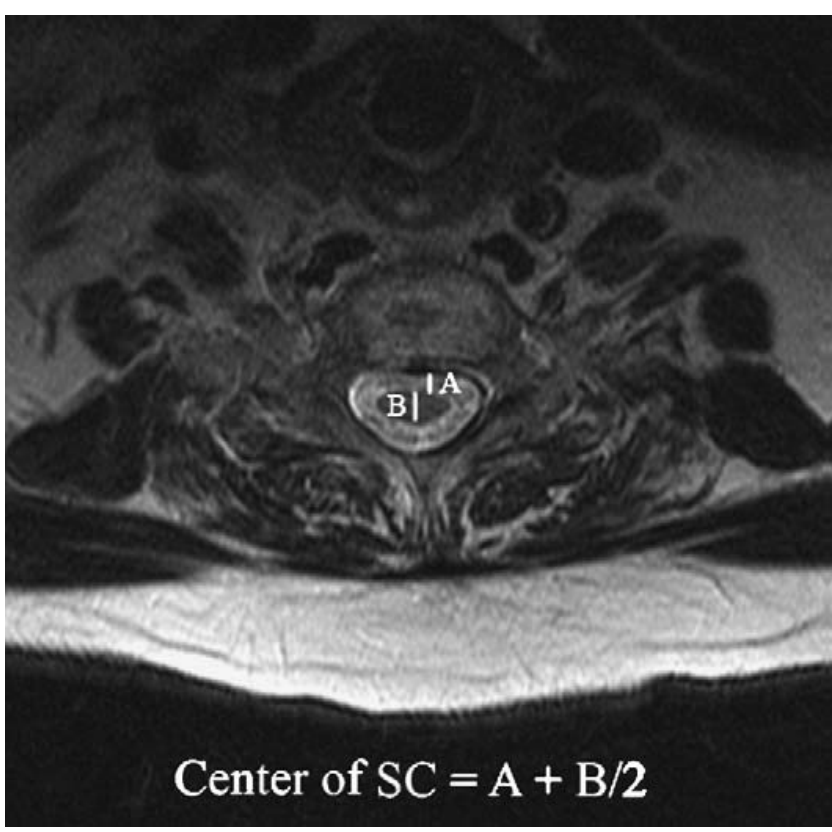

Figure 1. The midpoint of the spinal cord was determined by adding the anterior spinal cord space (A) to the half value of the AP spinal cord diameter (B/ $2)$. This value $(A+(B / 2))$ was determined at each decompressed level and averaged to give a global representation of spinal cord position.

space to the half value of the AP spinal cord diameter $(\mathrm{B} / 2)$. This value $(\mathrm{A}+(\mathrm{B} / 2))$ was determined at each decompressed level and averaged to give a global representation of spinal cord position (Figure 1). Spinal cord drift was quantified by subtracting the preoperative values from the postoperative values.

\section{Functional Outcome Measure}

The mJOA disability scale was calculated preoperatively and postoperatively to standardize each patient's neurological disability. ${ }^{16}$

\section{Statistical Methods}

The laminoplasty and laminectomy groups were analyzed on the basis of age, gender, number of levels affected, cord signal, time to postoperative MRI, spinal cord drift, and mJOA scores. Differences between the laminoplasty and laminectomy groups were assessed via the Welch $t$ test, while differences between the preoperative and postoperative period within each group were assessed via the 2-tailed paired-sample $t$ test (Table 1). Categorical variables, such as gender, were analyzed via $\chi^{2}$ analysis with the null hypothesis assuming no difference between groups. A 2-tailed paired-sample $t$ test was then used to compare within and between groups with respect to Cobb angles and drift, both preoperatively and postoperatively. Analysis of variance was used to compare differences in drift with respect to operative alignment within groups. Multivariate regression analysis was performed to compare spinal cord drift between groups with respect to the type of procedure, age, gender, time between preoperative and postoperative MRI, time between surgery and postoperative MRI, number of levels involved in the procedure, Cobb angles, and spinal alignment. The variables that were chosen for each model were determined based on availability of the data as well as on the authors' initial hypotheses about the effects of each variable on spinal cord drift. An $\alpha$ value of $\leq 0.05$ was used as the threshold for statistical significance. An $\alpha$ value of $0.05 \leq x \leq$ 0.1 was used as the threshold for statistical suggestiveness. Stata statistical software version 14.0 (StataCorp, College Station, Texas) was used to perform the analyses.

\section{RESULTS}

\section{Demographic and Clinical Data}

Group A $(\mathrm{n}=22)$ had a mean age of $54.5 \pm 9.6$ years (range $=42-77$ ) with a mean number of surgical levels of $2.9 \pm 1$ (range $=1-4$ ), while group $\mathrm{B}(\mathrm{n}=44)$ had a mean age of $65.1 \pm 10.1$ years (range $=38-89$ ) with a mean number of surgical levels of $3.5 \pm 0.8$ (range $=1-5)($ age,$P<.01$; levels, $P=.03$; Table 1 ).

\section{Radiographic Analysis}

The mean interval times from surgery to postoperative MRI in group A (laminoplasty group) and group B (LF group) were 10.08 and 10.67 months, respectively. Fifteen patients in group A, compared to 29 patients in group $\mathrm{B}$, had preoperative spinal cord T2-MRI signal hyperintensity, with no significant difference between groups. The laminoplasty group consisted of patients with either straight or lordotic spines, while almost a third of the LF patients demonstrated cervical kyphosis preoperatively. The mean preoperative Cobb angle (sagittal) was significantly greater for laminoplasty patients compared to patients who underwent LF.

The mean overall SC drift was significantly higher in the LF compared to the laminoplasty group (2.70 vs $1.71 \mathrm{~mm}, P=<.01$ ) (Figure 2). The same pattern was observed when comparing only the level with maximal drift in each patient between the 2 groups (Figure 1). In comparing individual cervical levels, 


\section{Spinal Cord Drift Following Posterior Decompression Surgery}

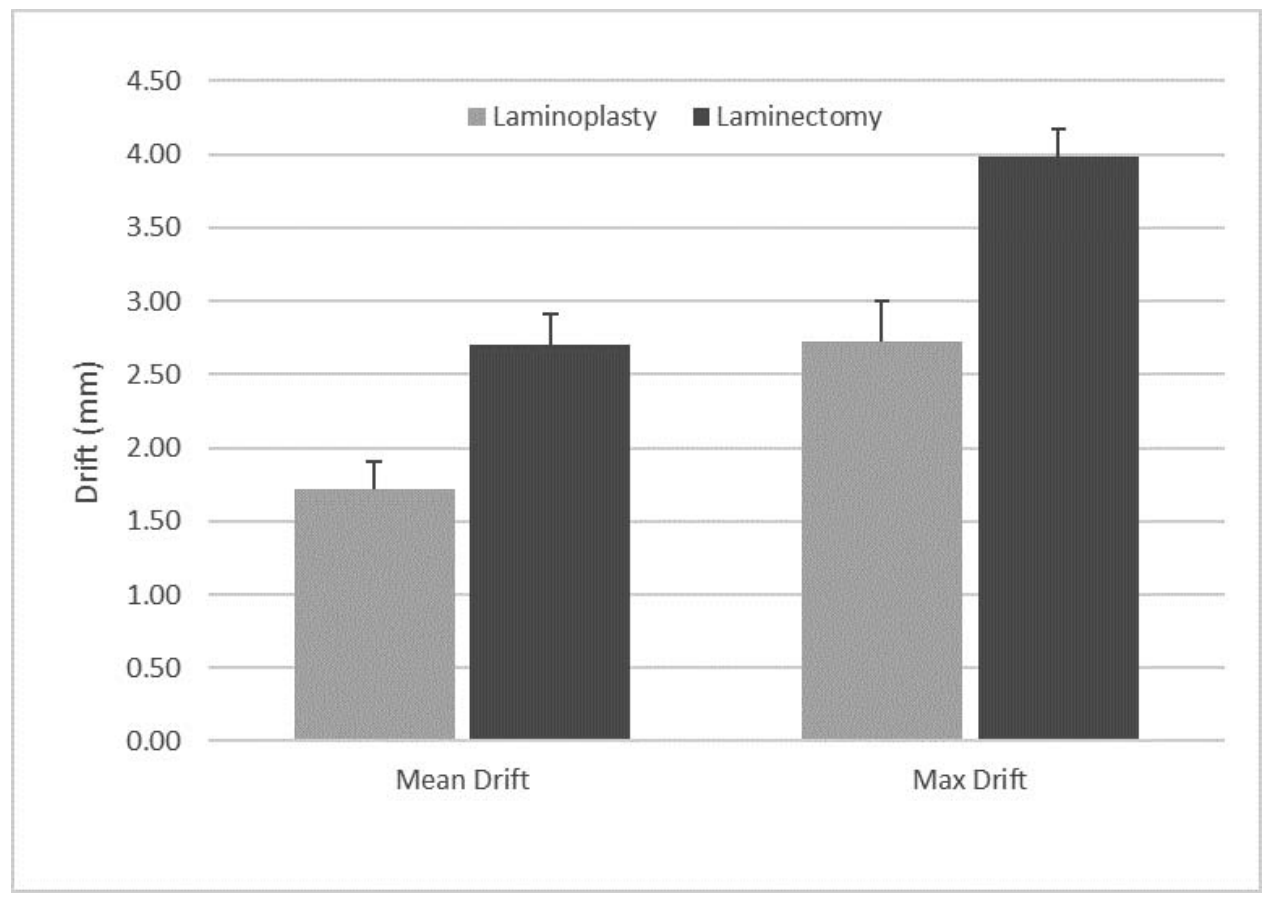

Figure 2. Mean and maximal cervical drift measured via postoperative magnetic resonance imaging.

more drift was generally observed in group B compared to group A, although statistical significance was reached only at $\mathrm{C} 6$ and $\mathrm{C} 7$ (C3: 1.30 vs $2.04 \mathrm{~mm}, P=.056$; C4: 2.10 vs $2.67 \mathrm{~mm}, P=.143$; C5: 2.24 vs $3.08 \mathrm{~mm}, P=.095$; C6: 1.88 vs $3.06 \mathrm{~mm}$, $P=.022 ; \mathrm{C} 7: 1.25$ vs $2.75 \mathrm{~mm}, P=.031$ ) (Figure 3 ). See Figure 4 for representative images of preoper- ative and postoperative MRIs following laminoplasty and LF.

Preoperatively, the mean Cobb angle was significantly greater for patients who underwent laminoplasty compared to patents who underwent LF $\left(11.5^{\circ}\right.$ vs $\left.4.9^{\circ}, P=.01\right)$. There was no statistically significant difference in mean drift within the LF

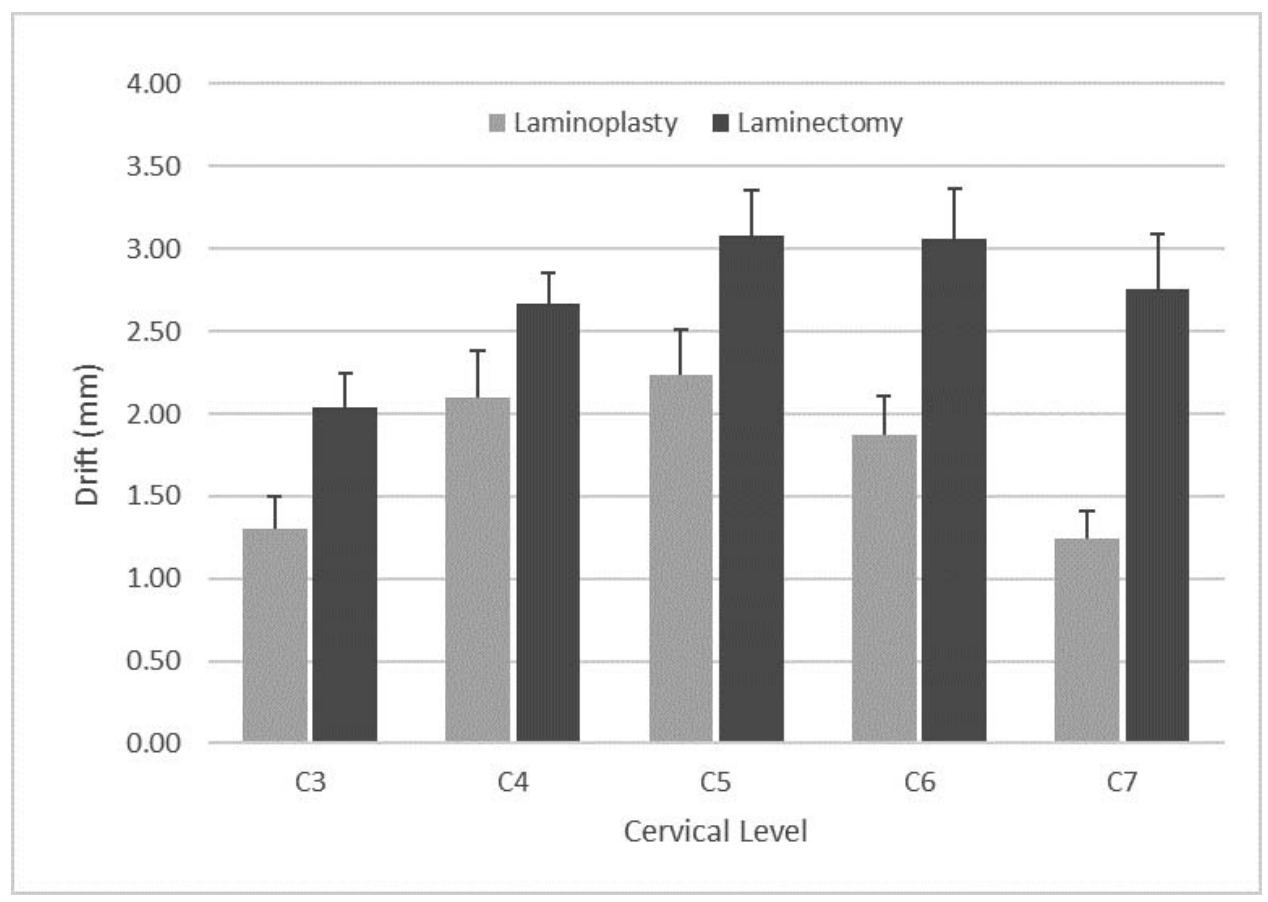

Figure 3. Mean cervical drift per level measured via postoperative magnetic resonance imaging. 


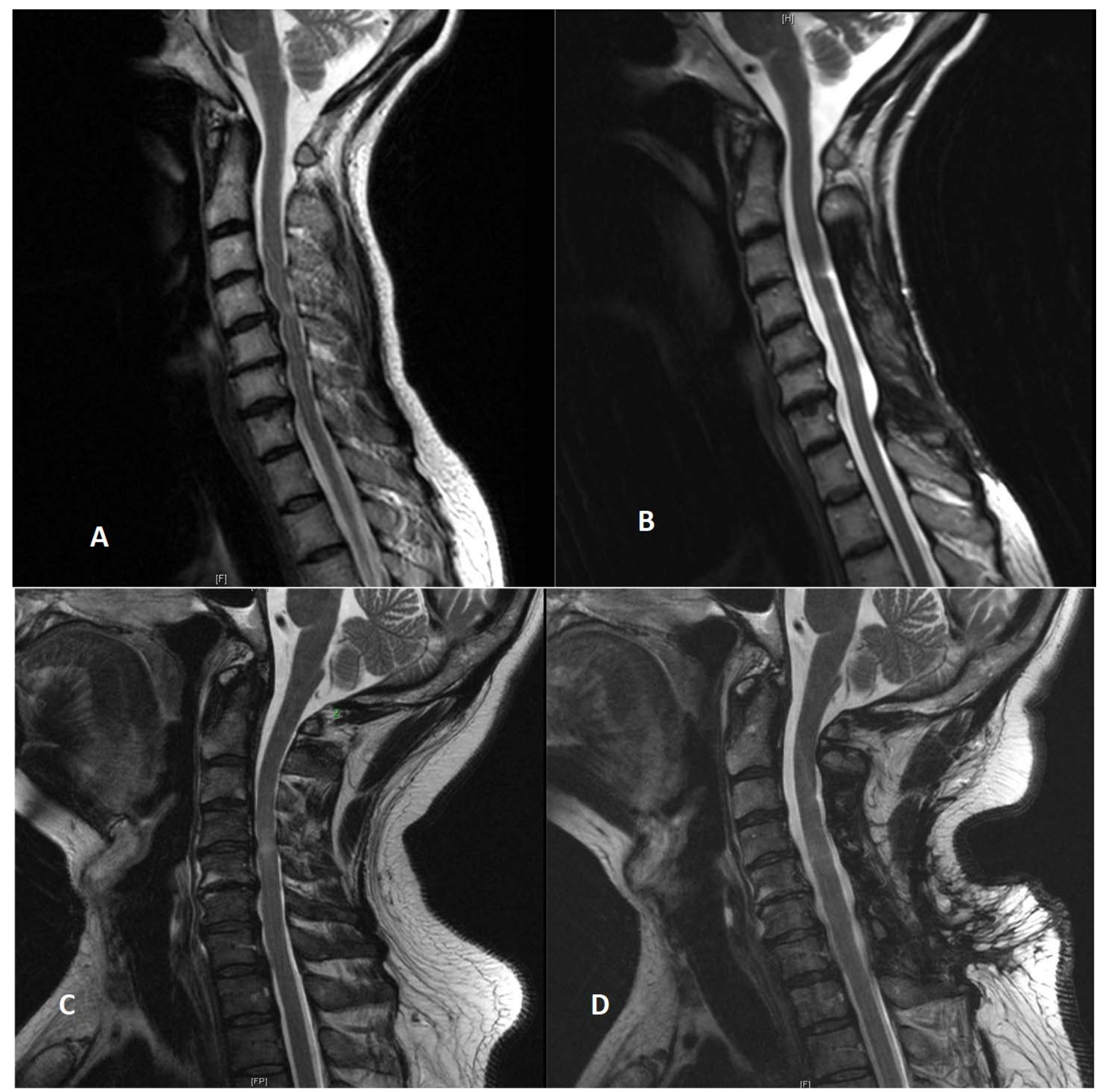

Figure 4. Preoperative (A) and postoperative (B) T2-sagittal magnetic resonance imaging (MRI) in a 57-y-old female who underwent a C3-C7 LF. Preoperative (C) and postoperative (D) T2-sagittal MRI in a 49-y-old male who underwent a C3-C7 laminoplasty.

group when comparing patients with different preoperative alignment (lordotic vs straight vs kyphotic patients, $P=.10)$. Postoperatively, the mean Cobb angle decreased for both groups $\left(-8.23^{\circ}\right.$ and $-3.8^{\circ}$ postoperatively in groups $\mathrm{A}$ and $\mathrm{B}$, respectively). However, the decrease was significantly greater following $\mathrm{LF}\left(-8.7^{\circ}\right.$ vs $\left.-3.27^{\circ}, P<.01\right)$. Subgroup analyses yielded no significant difference in drift observed within each group based on postoperative alignment (laminoplasty, $P=.10$; LF, $P=.60$ ).

Using multivariate logistic regression analysis, surgical treatment of CSM with LF was statistically suggestive of an increase in SC drift that was on average $0.94 \mathrm{~mm}$ greater than the drift seen with laminoplasty (95\% confidence interval: $0.15-2.04$ $\mathrm{mm}, P=.091)$. None of the other analyzed variables (including age, gender, number of affected levels, 
time between preoperative and postoperative MRI, time between surgery and postoperative MRI, preoperative and postoperative Cobb angles, and preoperative and postoperative spinal alignment) had statistically significant associations with spinal cord drift.

\section{Functional Outcomes}

The mean preoperative mJOA scores in groups A and $\mathrm{B}$ were 13.3 and 13.6 compared to mean postoperative mJOA scores of 15.3 and 15.9, respectively. Both groups showed an improvement in mJOA scores postoperatively compared to their preoperative values (group $\mathrm{A},+2.0, P=.012$; group $\mathrm{B} ;+2.4, P<.01)$. However, there was no difference in mJOA score improvement postoperatively between both groups $(P=.482)$.

\section{DISCUSSION}

LF and laminoplasty are the most common posterior procedures used in treating patients with CSM. ${ }^{2,3,11}$ The decompressive effect of these procedures is believed to occur primarily from dorsal drift of the spinal cord in an expanded canal. ${ }^{14,17}$ The plurality of studies investigating the association between preoperative alignment and drift following posterior procedures has been performed in patients who underwent laminoplasty. ${ }^{5-12}$ In many of these studies, the presence of preoperative cervical lordosis was deemed necessary to obtaining satisfactory outcome. Poor outcomes have been reported in those with preoperative kyphosis. ${ }^{10}$

Conversely, extensive review of the literature identified comparatively few studies directly addressing the relationship of preoperative sagittal alignment to drift following LF. The majority of the previously mentioned studies demonstrated no correlation between preoperative alignment and drift. ${ }^{13,14,18-22}$ These observations suggest that laminoplasty and LF may differ in the comparative amount of dorsal cord migration and in the mechanism through which drift is ascertained. Understanding these differences may help refine current indications and provide additional information on when one procedure may be preferable to the other.

This study was performed to directly compare the amount of spinal cord drift achieved in a cohort of CSM patients treated with LF or laminoplasty. As a secondary measure, the amount of drift obtained with either group was correlated with functional outcome using the mJOA score. In accordance with existing literature, laminoplasty was not offered to patients with kyphosis. However, the presence of mild kyphosis was not deemed a contraindication to LF. Consequently, the LF group contained a roughly equal number of patients with neutral, lordotic, or kyphotic alignment. Comparison of drift in this subgroup allowed investigation of the relationship between drift and preoperative alignment following LF if one existed.

We hypothesized that increased posterior drift of the cord would be observed following LF. The position of the spinal cord was noted preoperatively and postoperatively in patients undergoing LF and directly compared to preoperative and postoperative drift of those undergoing laminoplasty. In addition to radiographic comparisons, functional outcome was assessed by comparing preoperative and postoperative mJOA scores between and within the 2 groups. The 2 groups were comparable and statistically similar in many of the variables with the exception of age, which was noted to be lower in the laminoplasty group.

Mean observed drift was significantly higher following the LF group compared to following the laminoplasty group, although a third of patients in the former group had preoperative cervical kyphosis. This represented an average 57\% relative increase in posterior translation of the cord relative to the laminoplasty group. When comparing only the level with maximum drift in each patient, the LF group drifted an average of $46 \%$ more than the laminoplasty group. In comparing individual cervical levels, more drift was again observed following LF, though significance was reached only at C6 and C7. This finding is in accordance with previous studies demonstrating a pattern of increased posterior cord translation in the lower cervical segments compared to the upper segments. ${ }^{17,23}$

Furthermore, the observed differences suggest that drift following LF may be not be dependent on preoperative alignment to the same extent that it is following laminoplasty. This is supported by subanalysis of the LF group demonstrating no significant difference in drift when patients with preoperative neutral, straight, or kyphotic alignment were compared.

The mechanism responsible for the observed findings is unknown, although we believe that the dynamic of posterior cord drift may be different in 
patients undergoing laminectomy because the posterior elements are completely removed. On the contrary, the retained posterior elements after a laminoplasty may provide more resistance against posterior cord drift under certain circumstances. ${ }^{13,24}$

Postoperatively, loss of lordosis was observed in both groups. This was more pronounced following LF compared to laminoplasty. On average, postoperative alignment became kyphotic (mean cobb angle of -3.80 postoperatively vs +4.70 preoperatively) following LF. Despite this, increased drift was noted following LF. We speculate that the copious space available posteriorly and the elimination of potential cord tethers following LF lead to a broader range of dynamic cord movement not predicated on the effects of alignment. Conversely, limited posterior space and retained posterior elements following laminoplasty theoretically restrict the upper limit of dynamic cord motion in that setting. Under such conditions, obtaining adequate drift may be dependent on optimizing all favorable variables, including alignment.

Limitations of this study include the sample size and challenges inherent to a retrospective analysis. Furthermore, this study reviews the work of a single surgeon; therefore, process-based biases cannot be completely controlled for. In addition, the influence laminectomy or laminoplasty width on the role spinal cord drift was not assessed. A larger, randomized, multicenter study may be better equipped to definitively address this subject.

Although functional outcome (mJOA) was equivalent between the 2 groups, this study demonstrates that LF was associated with increased posterior drift of the cord compared to laminoplasty. Additionally, these results indicate that drift following LF may be independent of cervical alignment. If validated, these findings suggest that LF may provide satisfactory outcomes in the treatment of patients with CSM under certain circumstances where preoperative alignment precludes a laminoplasty.

\section{REFERENCES}

1. Fehlings MG, Tetreault LA, Wilson JR, Skelly AC. Cervical spondylotic myelopathy: current state of the art and future directions. Spine (Phila Pa 1976). 2013;38(22, suppl 1):S1-S8.

2. Matz PG, Anderson PA, Groff MW, et al. Cervical laminoplasty for the treatment of cervical degenerative myelopathy. J Neurosurg Spine. 2009;11(2):157-169.

3. Anderson PA, Matz PG, Groff MW, et al. Laminectomy and fusion for the treatment of cervical degenerative myelopathy. J Neurosurg Spine. 2009;11(2):150-156.

4. Edwards CC 2nd, Riew KD, Anderson PA, Hilibrand AS, Vaccaro AF. Cervical myelopathy: current diagnostic and treatment strategies. Spine J. 2003;3(1):68-81.

5. Sodeyama T, Goto S, Mochizuki M, Takahashi J, Moriya H. Effect of decompression enlargement laminoplasty for posterior shifting of the spinal cord. Spine (Phila Pa 1976). 1999;24(15):1527-1531; discussion 31-32.

6. Hirabayashi K, Toyama Y, Chiba K. Expansive laminoplasty for myelopathy in ossification of the longitudinal ligament. Clin Orthop Relat Res. 1999(359):35-48.

7. Yamazaki A, Homma T, Uchiyama S, Katsumi Y, Okumura H. Morphologic limitations of posterior decompression by midsagittal splitting method for myelopathy caused by ossification of the posterior longitudinal ligament in the cervical spine. Spine (Phila Pa 1976). 1999;24(1):32-34.

8. Aita I, Hayashi K, Wadano Y, Yabuki T. Posterior movement and enlargement of the spinal cord after cervical laminoplasty. J Bone Joint Surg Br. 1998;80(1):33-37.

9. Baba H, Uchida K, Maezawa Y, Furusawa N, Azuchi M, Imura S. Lordotic alignment and posterior migration of the spinal cord following en bloc open-door laminoplasty for cervical myelopathy: a magnetic resonance imaging study. $J$ Neurol. 1996;243(9):626-632.

10. Kimura I, Shingu H, Nasu Y. Long-term follow-up of cervical spondylotic myelopathy treated by canal-expansive laminoplasty. J Bone Joint Surg Br. 1995;77(6):956-961.

11. Chiba K, Toyama Y, Watanabe M, Maruiwa $\mathrm{H}$, Matsumoto M, Hirabayashi K. Impact of longitudinal distance of the cervical spine on the results of expansive open-door laminoplasty. Spine (Phila Pa 1976). 2000;25(22):2893-2898.

12. Fujimura Y, Nishi Y, Nakamura M. Dorsal shift and expansion of the spinal cord after expansive open-door laminoplasty. J Spinal Disord. 1997;10(4):282-287.

13. Tashjian VS, Kohan E, McArthur DL, Holly LT. The relationship between preoperative cervical alignment and postoperative spinal cord drift after decompressive laminectomy and arthrodesis for cervical spondylotic myelopathy. Surg Neurol. 2009;72(2):112-117.

14. Holly LT, Moftakhar P, Khoo LT, Shamie AN, Wang JC. Surgical outcomes of elderly patients with cervical spondylotic myelopathy. Surg Neurol. 2008;69(3):233-240.

15. Shaffrey CI, Wiggins GC, Piccirilli CB, Young JN, Lovell LR. Modified open-door laminoplasty for treatment of neurological deficits in younger patients with congenital spinal stenosis: analysis of clinical and radiographic data. J Neurosurg. 1999;90(suppl 2):170-177.

16. Kalsi-Ryan S, Singh A, Massicotte EM, et al. Ancillary outcome measures for assessment of individuals with cervical spondylotic myelopathy. Spine (Phila Pa 1976). 2013;38(22, suppl 1):S111-S122.

17. Suda K, Abumi K, Ito M, Shono Y, Kaneda K, Fujiya M. Local kyphosis reduces surgical outcomes of expansive open-door laminoplasty for cervical spondylotic myelopathy. Spine (Phila Pa 1976). 2003;28(12):1258-1262.

18. Hatta Y, Shiraishi T, Hase H, et al. Is posterior spinal cord shifting by extensive posterior decompression clinically significant for multisegmental cervical spondylotic myelopathy? Spine (Phila Pa 1976). 2005;30(21):2414-2419.

19. Ishihara A. Roentgenographic studies on the normal 
pattern of the cervical curvature. Nihon Seikeigeka Gakkai Zasshi. 1968;42(11):1033-1044.

20. Lee JY, Sharan A, Baron EM, et al. Quantitative prediction of spinal cord drift after cervical laminectomy and arthrodesis. Spine (Phila Pa 1976). 2006;31(16):1795-1798.

21. Chang V, Lu DC, Hoffman H, Buchanan C, Holly LT. Clinical results of cervical laminectomy and fusion for the treatment of cervical spondylotic myelopathy in 58 consecutive patients. Surg Neurol Int. 2014;5(suppl 3):S133-S137.

22. Houten JK, Cooper PR. Laminectomy and posterior cervical plating for multilevel cervical spondylotic myelopathy and ossification of the posterior longitudinal ligament: effects on cervical alignment, spinal cord compression, and neurological outcome. Neurosurgery. 2003;52(5):1081-1087; discussion $7-8$.

23. Yusof MI, Hassan E, Abdullah S. Predicted cervaical canal enlargement and effective cord decompression following expansive laminoplasty using cervical magnetic resonance imaging. Surg Radiol Anat. 2011;33(2):109-115.

24. Kohno K, Kumon Y, Oka Y, Matsui S, Ohue S, Sakaki S. Evaluation of prognostic factors following expansive laminoplasty for cervical spinal stenotic myelopathy. Surg Neurol. 1997;48(3):237-245.

Disclosures and COI: No funds were received in support of this work. No relevant financial disclosures are associated with this work.

Corresponding Author: Langston T. Holly, MD, David Geffen School of Medicine at UCLA, UCLA Spine Center, 1131 Wilshire Blvd, Suite 100, Santa Monica, CA 90401. Phone: (310) 267-5580; Email: 1holly@mednet.ucla.edu.

Published 16 April 2021

This manuscript is generously published free of charge by ISASS, the International Society for the Advancement of Spine Surgery. Copyright (C) 2021 ISASS. To see more or order reprints or permissions, see http://ijssurgery.com. 